\title{
Atrasos motores em crianças desfavorecidas socioeconomicamente. Um olhar Bioecológico
}

\author{
Motor delays in socioeconomically disadvantaged children: A Bioecological \\ look
}

\author{
Francisco Salviano Sales Nobre ${ }^{1,2}$, Paulo Felipe Ribeiro Bandeira ${ }^{3 *}$, Nadia Cristina Valentini ${ }^{3}$ \\ ARTIGO ORIGINAL | ORIGINAL ARTICLE
}

\begin{abstract}
Apoiado no Modelo Bioecológico, o objetivo do estudo foi investigar como os processos proximais eram conduzidos para desenvolver as habilidades motoras fundamentais nos microssistemas escola e projetos sociais esportivos e, verificar se a competência motora das crianças nessas habilidades motoras direcionava seu engajamento em outros contextos (intercâmbio social). Crianças do Ensino Fundamental I de um município localizado no Semiárido do Brasil foram avaliadas através do Test of Gross Motor Development2. A investigação do contexto de desenvolvimento e dos processos proximais realizou-se por meio de observação assistemática não participante e entrevistas a professores de educação física em diferentes escolas e comunidades. As entrevistas foram analisadas mediante o uso do Discurso do Sujeito Coletivo. Os resultados evidenciam uma prevalência de $100 \%$ de atrasos motores; desempenhos mais pobres foram evidenciados por meninas e em crianças não assistidas por programas sociais esportivos. A carência de aulas de educação física na escola e de propostas pedagógicas para promover o desenvolvimento de habilidades motoras foi observada no contexto, contribuindo para os atrasos detetados. Os microssistemas escolas e programas sociais são influenciados pela omissão do poder público (exo e macrosistemas), repercutindo no desempenho das crianças investigadas.
\end{abstract}

Palavras-chaves: Ambiente Sociocultural; Desenvolvimento Infantil; Proficiência Motora; Modelo Bioecológico.

\begin{abstract}
Supported on the bioecological model, the aim of this study was to investigate how the proximal processes to develop the fundamental motor skills in the microsystems of schools and sport social programs were conducted; and, if children' motor competency in those motor skills would guide their engagement in other contexts (community and social activities exchanges).Elementary school' children from a Brazilian' semiarid were assessed using the Test of Gross Motor Development-2. The investigations of the developmental context as well as the proximal process were conducted throughout non-participant and non-systematic observations and interviews with the physical education teachers from different schools and communities. The interviews were analyzed using the collective subject discourse. The results showed prevalence of $100 \%$ of motor delays; poorer performance was observed among girls and children that did not attended to social sport programs. The lack of physical education classes and pedagogical program to promote the development of motor skills were context observed, possibly contributing to the detected delays. The Microsystems schools and social programs are influenced by the omission of the public administration (exo e macro systems) reflecting in children performance.

Keywords: Cultural Characteristics; Child Development; Motor Skills; Bioecological Model.
\end{abstract}

Artigo recebido a 22.07.2015; Aceite a 03.02.2016

${ }^{1}$ Departamento de Educação Física - Instituto Federal de Educação, Ciência e Tecnologia - IFCE

${ }^{2}$ Grupo de Estudos em Desenvolvimento Motor e Saúde da Criança \& do Adolescente

${ }^{3}$ Escola de Educação Física, Fisioterapia e Dança, Universidade Federal do Rio Grande do Sul - UFRGS

* Autor correspondente: Universidade Federal do Rio Grande do Sul - UFRGS, Grupo de Avaliação e Intervenções Motora - GAIM, Rua Felizardo,750, Jardim Botânico, Lapex - Sala 206 E-mail: paulo.felipe@ufrgs.br 


\section{INTRODUÇÃO}

Estudiosos

contextualistas do desenvolvimento humano defendem que as condições socioeconômicas e o bairro em que a criança se desenvolve estão entre os principais fatores impactantes no seu desenvolvimento, não sendo, porém, a condição socioeconômica em si que interfere neste processo, mas seus fatores associados que determinam principalmente as oportunidades que são ofertadas no contexto (Papalia, Olds, \& Feldman, 2006). Isso parece ser particularmente verdadeiro para o domínio do desenvolvimento motor onde estudos têm evidenciado prevalência de atrasos motores em crianças que vivem em comunidades desfavorecidas socioeconomicamente (Booth et al., 1999; Cohen, Morgan, Plotnikoff, Callister, \& Lubans, 2014; Costa, Nobre, Nobre, \& Valentini, 2014; Spessato, Gabbard, Valentini, \& Rudisill, 2013).

Estabelecer uma relação de causa e efeito entre o desenvolvimento motor e o ambiente socioeconômico de escolares parece ser algo que deva ser evitado. Sobre o assunto Bronfenbrenner (2005) adverte que vincular uma característica desenvolvimental da pessoa a um único ambiente em que ela se desenvolve é um equívoco, ao que ele denominou de trabalhos de endereçamento social. É necessário considerar a rede social formada por diferentes ambientes em que a criança permeia, para entender o comprometimento do desenvolvimento de recursos pessoais específicos. Assim por exemplo, uma criança pode não estar tendo oportunidade para desenvolver habilidades motoras em um contexto, mas pode estar tendo em outro. Ademais, avaliar como tais oportunidades para promover o desenvolvimento motor são conduzidas é imperativo, o que talvez possa explicar, por exemplo, o porquê da prevalência de atrasos motores que tem sido identificada até mesmo em crianças assistidas por projetos sociais esportivos (Goodway, Robinson, $\&$ Crowe, 2010).

Gabbard e Krebs (2012) afirmam que não há como compreender o desenvolvimento sem considerar a relação que se estabelece entre indivíduo e contexto e, sugeriram que a teoria bioecológica do desenvolvimento humano de
Bronfenbrenner poderia fornecer um aporte metodológico para explicar determinados fenômenos relacionados à área. $\mathrm{Na}$ teoria bioecológica o desenvolvimento humano é explicado a partir dos seus quatro pilares: aPessoa, o Processo, o Contexto e o Tempo (Modelo PPCT). O Processo é o constructo central do modelo e diz respeito à relação bidirecional que se estabelece entre o indivíduo e o (s) ambiente (s) imediato (s) que a pessoa se desenvolve ao longo do tempo. A forma como o indivíduo explora seu ambiente físico e os objetos e símbolos nele presentes, bem como a forma como experiência suas relações sociais com indivíduos mais experientes, explica porque os processos proximais são considerados os mecanismos fundamentais para o desenvolvimento humano. Entretanto, Bronfenbrenner \& Morris (2006) advertem que o processo varia consideravelmente de acordo com as características da pessoa, dos contextos e do tempo em que os processos proximais ocorrem.

No Modelo PPCT, os ambientes imediatos que a criança participa ativamente são os microssistemas (ex: escola, projetos sociais esportivos - PSE, comunidade); a rede social formada entre os microssistemas é definida como mesossistema; os ambientes remotos que apesar de a criança não participar ativamente, tem seu desenvolvimento afetado pelas decisões que ocorrem neles chama-se exossistema (ex: secretaria de educação, secretarias de esporte, etc.). O contexto maior, definido como macrossistema é formado pelos microssistemas, mesossistemas, exossistemas característicos de uma cultura ou subcultura; e revela o sistema de crenças, recursos, estruturas, riscos, oportunidades, intercâmbios sociais, estilos e opções de vida compartilhada por um grupo. $\mathrm{O}$ que ocorre no(s) exossistema(s) ou microssistema(s) pode ser influenciado por esse contexto maior (Bronfenbrenner \& Morris, 2006).

Bronfenbrenner e Morris (2007) sugerem que particularmente três características da pessoa podem afetar o desenvolvimento humano: os recursos (habilidades, experiências e conhecimento) necessários para o funcionamento eficaz dos processos proximais; 
as disposições (característica motivacional) que podem colocar os processos proximais em movimento em um domínio de desenvolvimento particular e sustentar o seu funcionamento, e a demanda (característica que convida ou desencoraja reações da pessoa em seu ambiente social) que pode favorecer ou prejudicar o funcionamento dos processos proximais. Essas características interagem entre si atuando na força e direção dos processos proximais (Bronfenbrenner \& Morris, 2007).

Mediante o modelo bioecológico pode-se inferir então, que as habilidades motoras fundamentais se mostram como uma consequência de como os processos proximais são conduzidos nos diferentes microssistemas responsáveis por promover este recurso pessoal e, que sendo a relação entre indivíduo e contexto bidirecional, é provável que os atrasos motores em escolares possam inibir a ação dos mesmos em outros contextos que requeira proficiência em habilidades motoras. Esta hipótese é pertinente, visto que as habilidades motoras fundamentais são consideradas pré-requisitos para habilidades motoras especializadas que são empregadas nos esportes, jogos, danças, ginásticas e outras atividades da cultura corporal (Barnett, Beurden, Morgan, Brooks, \& Beard, 2009).

Apesar da importância dos estudos que alertam para o fato de que a prevalência de atrasos motores ocorre principalmente em crianças desfavorecidas socioeconomicamente (Booth et al., 1999; Cohen et al., 2014; Costa et al., 2014; Spessato et al., 2013), cabe ressaltar que esses estudos não avançaram para além da descrição do fenômeno, havendo assim a necessidade de procurar explicar por que o mesmo acontece. Assim, atendendo as sugestões propostas por Gabbard e Krebs (2012), apoiado na teoria bioecológica, este trabalho objetivou investigar os processos proximais para o desenvolvimento de habilidades motoras fundamentais de crianças de ambos os sexos nos microssistemas escola e projetos sociais esportivos e, verificar se a competência motora das crianças nessas habilidades motoras afetava sua participação em atividades esportivas em outros contextos.
Baseado no modelo bioecológico (Bronfenbrenner \& Morris, 2007) e estudos prévios (Spessato et. al. 2012; Goodway et al., 2010), o presente estudo considerou as seguintes hipóteses: a) de forma geral, crianças desfavorecidas socioeconomicamente apresentariam atrasos motores, inclusive aquelas assistidas por PSE; b) tais atrasos seriam mais pronunciados em crianças do gênero feminino; c) tais atrasos seriam influenciados por contextos imediatos (microssistemas) e remotos (exossistema e macrossistema); d) as habilidades motoras fundamentais das crianças impactam no intercâmbio social das mesmas.

\section{MÉTODO}

Neste estudo, de delineamento pessoaprocesso-contexto-tempo, o pesquisador investiga informações sistemáticas em três domínios específicos: (1) o contexto, no qual o desenvolvimento ocorre, (2) as características pessoais, biológicas ou psicológicas das pessoas presentes nesse contexto, (3) o processo, através do qual o desenvolvimento é manifestado, e sua associação com o tempo cronológico e sóciohistórico. Além disso, o pesquisador está preocupado com os efeitos bidirecionais entre a pessoa e o contexto (Bronfenbrenner, 2005, p. 77).

\section{Contexto e Participantes}

A Região Nordeste do Brasil é considerada a mais desfavorecida socioeconomicamente do País. O Semiárido Nordestino, que corresponde a quase $90 \%$ dessa Região é onde concentra os maiores índices de pobreza. $\mathrm{O}$ estudo foi realizado em um município localizado na Região Sertão Central do Ceará, Brasil, onde dos 80604 habitantes, $71.3 \%$ residem na zona urbana. A administração pública juntamente com o comércio e o setor de serviços responde por 81.6 $\%$ dos empregos formais. Destaca-se que $27.9 \%$ da população economicamente ativa apresenta rendimento domiciliar per capita mensal entre $1 / 2$ e 1 salário mínimo, $55.1 \%$ menos de $1 / 2$ salário mínimo e $20.83 \%$ apresentam renda de até $\mathrm{R} \$ 70.00$, o que os classificam como extremamente pobres (Instituto de Pesquisa e Estratégia Econômica do Ceará [IPECE], 2011). 
No momento da pesquisa 2067 crianças frequentavam o Ensino Fundamental I (EFI) da rede urbana. Dessas, participaram da pesquisa por voluntariado66 crianças, 37 meninos $(8.04 \pm 0.94$ anos) e 29 meninas $(8.05 \pm 0.77$ anos) tiveram as habilidades motoras fundamentais avaliada. As crianças eram oriundas de 6 escolas de dois bairros classificados como em situação de risco social e não apresentavam histórico de deficiência sensóriomotora ou de incapacidade física. A utilização de uma região específica justifica-se pelo fato de que no Modelo Bioecológico o pesquisador precisa inserir-se na comunidade para investigar como ocorre os processos proximais para promover o desenvolvimento infantil.

Oito professores de educação física - EF (6 homens e 1 mulher) forneceram informações sobre como os processos proximais operavam nos microssistemas. Crianças e seus representantes legais, bem como os professores de EF assinaram o termo de consentimento informado. Esta pesquisa foi aprovada pelo Comitê de Ética em Pesquisa da Universidade Federal do Rio Grande do Sul, Processo no 1986.

\section{Instrumentos}

Habilidades motoras Fundamentais

Foi utilizado o Teste Gross Motor Development 2 - TGMD-2 (Ulrich, 2000) validado para população brasileira por Valentini (2012). O TGMD-2 é composto por duas subescalas, habilidades de locomoção e de controlo de objeto e foi projetado para medir elementos critério de desempenho nas habilidades motoras básicas em crianças de 3 a10 anos. O teste inclui 12 itens: seis habilidades locomotoras - HLOC (correr, galope, salto com um pé, salto passada, salto horizontal, e corrida horizontal) e seis habilidades de controlo de objetos HCO (quicar a bola, rebater, pegar, chutar, arremesso por cima e arremesso por baixo). Cada habilidade é avaliada para a presença ou ausência de 3 a 5 critérios de desempenho. $O$ participante recebe um 1 se demonstrar o comportamento ou 0 se não realizar. A pontuação é somada para cada habilidade específica e em todas as 12 habilidades, criando um escore bruto para as sub- escalas de habilidades de locomoção e controlo de objeto. A soma dos critérios observados para cada subescala compreende a pontuação total em escores brutos (0-48 pontos).

\section{Entrevistas:}

O procedimento de entrevista se baseou na analise do Discurso do Sujeito Coletivo - DSC (Lefèvre \& Lefèvre, 2005). O DSC diz respeito a uma proposta metodológica de organização e tabulação de dados qualitativos de natureza verbal fazendo uso das figuras metodológicas: Expressões-Chaves - ECH (trechos ou transcrições literais do discurso que revelam a essência do depoimento); Idéias Centrais - IC (expressão linguística que descreve de maneira mais sintética o sentido de cada um dos discursos); e, Ancoragens - AC (manifestação linguística explícita de uma dada teoria, ideologia ou crença que o entrevistado professa). As entrevistas foram conduzidas na comunidade com o uso de um gravador digital de voz DVR (2926. S Powerpack $\left.{ }^{\circledR}\right)$, para posterior transcrição.

\section{Procedimentos}

As avaliações das habilidades motoras fundamentais foram conduzidas por dois professores treinados, no ginásio de esportes da comunidade, as crianças eram avaliadas em duplas, os testes tinham uma duração média de 20 minutos por dupla.

Para investigar como os processos proximais promoviam a proficiência motora nos microssistemas, bem como ocorria as interconexões com o exo e o macrossistema, o pesquisador se inseriu ecologicamente na comunidade (Cecconello \& Koller, 2003) permanecendo na mesma durante 6 meses e, se valendo de observação assistemática não participante (Rudio, 1978). Por fim, o tempo foi analisado de dois modos: o tempo cronológico que orienta as expectativas para o nível de proficiência motora desejada para a faixa etária na qual as crianças se encontravam e, o tempo sóciohistórico que envolve as ações favorecedoras ou inibidoras para o desenvolvimento das habilidades motoras fundamentais. 


\section{Análise estatística}

Medidas de tendência central e dispersão foram utilizadas para descrever as características de proficiência motora das crianças. O teste Shapiro Wilk foi utilizado para testar a normalidade dos dados. Visto que os dados tinham distribuição simétrica optou-se porestatística inferencial por meio do Teste t de Student para comparar o desempenho motor entre meninos e meninas e entre participantes e não participantes de projetos sociais.ANOVA (análise de variância) foi utilizada para comparar o desempenho motor de meninos e meninas. $\mathrm{O}$ tamanho do efeito para as comparações resultantes do teste " $\mathrm{t}$ " foi estimado através do valor do "d" de Cohen.

\section{RESULTADOS}

\section{Desempenho motor:}

No geral as crianças de ambos os sexos obtiveram pontuação média inferior a 25 pontos para habilidades de locomoção (HLoc) e abaixo de 30 pontos para habilidades de controle de objeto (HCo), o que conforme Ulrich (2000) os classificam abaixo do percentil 5 , ou seja, com $100 \%$ de atrasos motores. A Tabela 1 evidencia respectivamente o desempenho em HLoc e HCoentre os sexos, mostrando a inexistência de diferenças significativas entre os sexos para o desempenho em HLoc $(\mathrm{p}=0,71)$ e HCo $(0,052)$. Entretanto, os meninos apresentaram diferenças significativas para as HCo de chutar e arremessar.

Tabela 1

Desempenho Motor: média e comparaçôes de gênero em cada habilidade de locomoção e de controle de objetos.

\begin{tabular}{|c|c|c|c|c|}
\hline TGMD Subtestes \& Habilidades Motoras & Meninos M(DP) & Meninas M(DP) & $\mathrm{p}$ & $d$ \\
\hline Subteste LOC & $23.6(4.5)$ & $24.0(4.3)$ & 0.710 & 0.09 \\
\hline Corrida & $4.5(1.4)$ & $4.6(1.1)$ & 0.887 & 0.08 \\
\hline Galope & $4.0(2.0)$ & $4.1(1.5)$ & 0.705 & 0.06 \\
\hline Saltar1 pé & $4.4(1.9)$ & $4.2(1.8)$ & 0.714 & 0.11 \\
\hline Passada & $3.5(1.0)$ & $3.4(1.0)$ & 0.677 & 0.10 \\
\hline Salto Horizontal & $3.6(1.1)$ & $3.8(1.5)$ & 0.738 & 0.16 \\
\hline Corrida Lateral & $3.6(1.6)$ & $4.0(1.3)$ & 0.319 & 0.28 \\
\hline Subteste C.Obj & $27.1(3.5)$ & $24.6(4.8)$ & 0.052 & 0.50 \\
\hline Rebater & $4.8(1.1)$ & $5.0(1.7)$ & 0.717 & 0.15 \\
\hline Quicar & $4.2(2.0)$ & $3.9(1.6)$ & 0.406 & 0.17 \\
\hline Receber & $4.1(1.0)$ & $4.0(1.3)$ & 0.726 & 0.09 \\
\hline Chutar & $5.2(1.2)$ & $4.2(1.5)$ & $0.004^{*}$ & 0.76 \\
\hline Arremesso & $4.9(1.5)$ & $3.9(1.7)$ & $0.012^{*}$ & 0.64 \\
\hline Rolar a bola & $3.8(1.3)$ & $3.7(1.4)$ & 0.742 & 0.08 \\
\hline
\end{tabular}

${ }^{*}$ Diferenças significativas no teste- $t$ para amostras independentes $\mathrm{p}<0,05$; Tamanho de efeito d de Cohen largo $>0,8$; Subteste Loc: Subteste Locomoção; Subteste C.Obj: Subteste Controle de Objeto; $d$ : d de Cohen

Tabela 2

Desempenho Motor: média, desvio padrão e comparaçôes de gênero nas habilidades de locomoção e controle de objetos entre assistidos e não assistidos por PSE.

\begin{tabular}{|c|c|c|c|c|c|c|c|c|}
\hline \multirow{2}{*}{$\begin{array}{l}\text { TGMD Subtestes \& } \\
\text { Habilidades Motoras }\end{array}$} & \multicolumn{4}{|c|}{ Meninos } & \multicolumn{4}{|c|}{ Meninas } \\
\hline & $\begin{array}{l}\text { Assistidos } \\
\text { M(DP) }\end{array}$ & $\begin{array}{l}\text { Não assistidos } \\
\text { M(DP) }\end{array}$ & $\mathrm{p}$ & $D$ & $\begin{array}{l}\text { Assistidos } \\
\text { M(DP) }\end{array}$ & $\begin{array}{c}\text { Não assistidos } \\
\text { M(DP) }\end{array}$ & $p$ & $d$ \\
\hline Subteste LOC & $25.9(3.1)$ & $21.2(4.5)$ & 0.001 & 1.25 & $25.9(2.6)$ & $19.2(4.5)$ & 0.001 & 1.86 \\
\hline Galope & $4.6(1.6)$ & $3.3(2.3)$ & $0.029^{*}$ & 0.75 & $4.6(1.2)$ & $2.9(1.5)$ & $0.004^{*}$ & 1.37 \\
\hline Saltar 1 pé & $5.4(1.3)$ & $3.3(1.9)$ & $0.001^{*}$ & 1.66 & $5.0(1.1)$ & $2.1(1.6)$ & $0.001^{*}$ & 2.46 \\
\hline Passada & $3.5(1.0)$ & $3.5(1.0)$ & 0.939 & 0.38 & $3.3(1.1)$ & $3.6(0.9)$ & 0.446 & 0.30 \\
\hline Salto Horizontal & $4.0(0.7)$ & $3.3(1.4)$ & $0.046^{*}$ & 1.01 & $4.2(0.9)$ & $2.6(2.3)$ & $0.012^{*}$ & 0.94 \\
\hline Corrida Lateral & $4.2(1.2)$ & $2.9(1.7)$ & $0.013^{*}$ & 1.11 & $4.4(1.3)$ & $2.9(0.8)$ & $0.005^{*}$ & 1.22 \\
\hline Subteste C.Obj & $28.0(2.9)$ & 26.1(3.9) & 0.086 & 0.57 & $25.6(3.8)$ & $22.0(6.3)$ & 0.070 & 0.31 \\
\hline Rebater & $4.9(1.0)$ & $4.8(1.3)$ & 0.761 & 0.10 & $5.4(1.3)$ & $3.8(2.1)$ & $0.015^{*}$ & 0.94 \\
\hline Quicar & $4.8(1.3)$ & $3.6(2.3)$ & 0.048 & 0.94 & $4.5(0.9)$ & $2.1(1.9)$ & $0.001^{*}$ & 1.66 \\
\hline Receber & $3.9(0.2)$ & $4.4(1.2)$ & 0.149 & 0.78 & $4.6(1.0)$ & $5.3(1.2)$ & 0.456 & 0,65 \\
\hline Chutar & $5.1(1.1)$ & $5.2(1.3)$ & 0.983 & 0.09 & $4.1(1.2)$ & $4.3(1.5)$ & 0.864 & 0,15 \\
\hline Arremesso & $5.0(1.2)$ & $4.7(1.8)$ & 0.579 & 0.23 & $4.1(1.3)$ & $3.1(2.3)$ & 0.144 & 0,55 \\
\hline Rolar a bola (8) & $4.3(0.9)$ & $3.4(1.6)$ & $0.046^{*}$ & 0.84 & $3.8(1.3)$ & $3.5(1.8)$ & 0.613 & 0.20 \\
\hline
\end{tabular}

* Diferenças significativas no teste- $t$ para amostras independentes $\mathrm{p}<0,05$; \# tamanho de efeito largo > 0,8; Subteste Loc: Subteste Locomoção; Subteste C.Obj: Subteste Controle de Objeto; $d$ : d de Cohen 
Evidências científicas sugerem que projetos sociais com foco no esporte podem exercer um importante papel sobre o desenvolvimento motor de escolares (Goodway et al., 2010).

A Tabela 2 descreve as características de desempenho motor de escolares assistidos e não assistidos por projetos sociais esportivos (PSE).

Pode-se constatar na Tabela 2 que apesar de todas as crianças do estudo apresentarem prevalência de atrasos motores, seus efeitos são menos nocivos entre aquelas assistidas por PSE. A tabela 2 revela assim, que em relação às HLocos meninos e meninas assistidos por PSE apresentaram diferenças significativas em relação aos seus pares não assistidos para habilidades de galopar, saltar com um pé, salto horizontal e corrida lateral. Nas HCo os meninos assistidos por PSE demonstraram diferença significativa em relação aos não assistidos apenas para habilidade de rolar a bola e, as meninas assistidas quando comparadas as não assistidas demonstraram diferenças significativa para o desempenho das habilidades de rebater e quicar a bola.

\section{Sobre os processos proximais no microssistema escola:}

O estudo observacional permitiu constatar que as aulas de educação física no Ensino Fundamental I (EFI) aconteciam apenas em algumas escolas conforme o interesse dos gestores escolares. Ao questionar os professores sobre esse assunto verificou-se discursos divergentes.

\section{DSC 1.1}

IC: A falta de persistência temporal nas aulas de EF não favorece a proficiência motora.

Do segundo ao quinto ano eles já passam ter aulas com professores de educação física. $\mathrm{O}$ município também disponibilizou 10 monitores para que pudessem estar trabalhando com essas crianças. Foi feito um convênio com a faculdade daqui para que os alunos do $5^{\circ}$ e $6^{\circ}$ semestre possam fazer estágio. No entanto, nós temos um déficit nas nossas aulas de educação física porque trabalhamos apenas uma aula por semana.
DSC 1.2.

IC: a Lei e a vontade política não garantem o exercício do PEF no EFI.

A Educação Física na sua Lei 9394/96, fala da obrigatoriedade da nossa disciplina no âmbito escolar, mas infelizmente, a educação física fica desnorteada em relação a esse compromisso. Aqui na cidade nós só temos aula para crianças de 3 a 10 anos nos colégios particulares. Eu ando nas aulas e acompanho uma pequena tortura, onde as polivalentes se sentem despreparadas. Elas falam que viram apenas na grade curricular uma disciplina voltada para recreação e lazer. Quando os alunos chegam ao Ensino Fundamental II, eles têm uma dificuldade imensa de girar, saltar..., e isso foi prejudicado por falta de orientação do profissional de educação física nas séries iniciais.

Ao perguntar sobre os conteúdos que eram explorados nas as aulas de educação física e sobre as condições de materiais disponibilizados, o DSC 2.1 denunciou uma falta de recursos materiais que dessem suporte à ação pedagógica do professor. De forma mais comprometedora ainda, o DSC 2.1 revela a inexistência de uma proposta didática pedagógica para promover a proficiência motora das crianças.

DSC 2.1.

IC: os conteúdos das aulas se restringem aos jogos e atividades recreativas e os recursos materiais são escassos.

No Ensino Fundamental I onde eu atuo, como os recursos são pouquíssimos, as aulas são desenvolvidas em forma de brincadeiras, jogos recreativos, jogos de rua, jogos populares e jogos cooperativos, ocorrendo uma vez por semana durante trinta minutos, o que é insuficiente. Eu pude observar que em algumas escolas o professor polivalente deixa a criança a vontade. Eles ficam só sentados e os meninos ficam na sala de aula brincando. Quanto aos materiais, eu posso dizer que praticamente não tem material pra gente trabalhar. Se quiser eu mostro, eu abro o armário. 


\section{Sobre os processos proximais no microssistema PSE:}

A pesquisa observacional permitiu constatar a existência de três PSE nos dois bairros aonde residiam as crianças participantes deste estudo. Porém, nem um desses vinculados ao Ministério da Educação ou Esporte. Desses três PSE, dois faziam uso de práticas motoras na sua proposta educacional. Em ambos os projetos era rara a participação de crianças com idade entre 7 e 10 anos em práticas motoras orientadas.

Constatou-se por meio do estudo observacional que em um dos PSE havia pedagogos e professores de EF, porém, as práticas motoras orientadas estavam restritas a jogos cooperativos e esportes, mais especificamente futebol e natação. No outro PSE, além da carência de pessoas com qualificação profissional para exercer as atividades docentes verificou-se uma segregação de gênero para algumas atividades. As meninas praticavam basicamente dança. Algumas delas praticavam capoeira e natação. Entre os meninos, além da natação e da capoeira, a única atividade esportiva ofertada era o futebol.

\section{Sobre a relação bidirecional criança-contexto}

Quando indagados sobre como as crianças promoviam seu o intercâmbio social por meio de atividades da cultura corporal, o DSC 3.1 aponta para a falta de compromisso do poder público em utilizar as atividades lúdicas e/ou esportivas como um fator de intercâmbio social e, que as atividades só oportunizam crianças com melhores níveis de proficiência motora.

\section{DSC 3.1 dos Professores de Educação Física:}

AC: o intercâmbio social por meio de práticas motoras só ocorre por iniciativa isolada dos professores e contempla apenas os mais habilidosos.

Nós tivemos aqui no ano passado alguns jogos que a gente fazia convite e havia um intercambio de um bairro para outro. Mas, o que eu observei e o que eu observo, é que para essa faixa etária de 7 a 10 anos, nós estamos a quem do que realmente acontecesse na comunidade e, na cidade como um todo. Existem os jogos, as olimpíadas escolares que são organizadas pelo governo federal; o governo estadual organiza a parte que cabe ao estado, e o município deveria organizar a parte que cabe ao município.

\section{DISCUSSÃo}

Os atrasos motores detetados nesta pesquisa ratificam a hipótese "a", evidenciando que crianças desfavorecidas economicamente têm o desenvolvimento de suas habilidades motoras fundamentais comprometido (Goodway et al., 2010) e, respaldando os resultados de estudos prévios (Booth et al., 1999; Cohen et al., 2014; Costa et al., 2014; Spessato et al., 2013). Resultados conflituosos com a literatura somente fora observado para a inexistência de diferenças significativas no escore bruto total de HCo entre os sexos, negando segunda hipótese deste estudo. De forma geral, estudos tem demonstrado que os meninos apresentam diferenças significativas no desempenho de $\mathrm{HCo}$ quando comparado as meninas (Goodway et al., 2010; Spessato et al., 2013). Diferenças significativas entre os sexos somente fora observado para as habilidades de chutar e arremessar, alinhando-se ao que também fora identificado em escolares portugueses (Afonso et al., 2009) e espanhóis (Mesa, Estrada, Prado, \& González, 2009). Esses resultados ratificam as influências culturais que oferecem mais oportunidades aos meninos em atividades que requerem essas habilidades.

As diferenças significativas entre crianças assistidas e não assistidas por PSE apenas para o escore bruto total de HLoc podem ser justificadas pelas atividades desenvolvidas nos PSE que exploravam prioritariamente práticas motoras que requeriam mais essas habilidades (dança e capoeira).Diferenças significativas para $\mathrm{HCo}$ de rolar a favor dos meninos assistidos e de quicar e rebater a favor das meninas assistidas, não podem ser explicadas pelos processos proximais desencadeados no mesossistema escola e PSE, visto que em ambos microssistemas não era dada às crianças as oportunidades nas atividades que desenvolvessem tais habilidades. Assim é possível que estas habilidades possam está sendo desenvolvidas em outro microssistema não tenha sido investigado neste estudo. 
Visto que a única atividade esportiva que envolvia HCo era o futebol, causa estranheza o fato da inexistência de diferenças significativas na habilidade de chutar entre meninos assistidos e não assistidos por PSE, o que sugere pouca eficiência desse microssistema para desenvolver as habilidades motoras relacionadas ao futebol. No geral, os resultados deste trabalho atestam que as habilidades motoras fundamentais das crianças do Semiárido não estão sendo desenvolvidas nem na escola e nem nos PSE, corroborando com o estudo de Goodway et al., (2010) a qual sugere a necessidade de mudanças nas propostas pedagógicas adotadas nos PSE para que os mesmos possam compensar os atrasos motores infantis. Esta sugestão parece pertinente, visto que os PSE no Brasil têm recebido do poder público federal mais recursos do que o que é repassado para EF escolar (Mendes \& Azevêdo, 2010).

Esta afirmativa encontra apoio nos DSC 1.1 que revela que quando as crianças tinham aulas de EF, essas ocorriam dentro de um cronossistema que não possibilitava incitar os processos proximais (Bronfenbrenner \& Morris, 2006). O DSC 1.2 mostra o sistema aninhado de ambientes (Bronfenbrenner \& Morris, 2006), aonde o que vem ocorrer no microssistema escola é influenciado pelas decisões que são tomadas no exossistema (Prefeitura/Secretaria de Educação), confirmando a terceira hipótese deste estudo. Por sua vez, esta desarticulação entre o exo e o microssistema é influenciada pelo macrossistema que determina as Leis para o funcionamento $\mathrm{EF}$ escolar. Apesar do inciso $3^{\circ}$ do Art. 26 da Lei 9.394/96 de Diretrizes e Bases da Educação LDB -determinar que: "a educação física, integrada à proposta pedagógica da escola, é componente curricular obrigatório da educação básica (...)" (Brasil LDB, 2010, p. 3), a Lei não estabelece o numero de aulas de EF para cada ciclo de ensino. Ainda, amparado nas brechas da Lei, Resolução do Conselho de Educação do Ceará (CEC) 412/200624 diz que as aulas de educação física no Ensino Fundamental I (EFI) deve estar justificada no projeto político pedagógico da escola, ser atribuição da professora polivalente e ministrada na forma de recreação.
Conforme Bronfenbrenner e Morris (2006), uma legislação diz respeito a um macrossistema, que por sua vez interfere nas ações dos exossistemas e microssistemas. De fato, se a obrigatoriedade das aulas de EF no EFI estiverem associadas aos interesses da proposta pedagógica da escola, tem-se que o exossistema (Secretaria de Educação Municipal) não garante que os alunos do $1^{\circ}$ ao $5^{\circ}$ ano venham ter acesso às aulas de EF como evidenciado no DSC 1.2. Ou seja, a disciplina existe apenas para efeitos legais. Problema este que se reproduz em outras regiões do país (Spessato et al., 2013).

Ainda, verifica-se neste estudo que o macrossistema interfere negativamente na forma como os processos proximais são operados no microssistema. Quando a Lei estabelece que as aulas devam ser realizadas na forma de recreação, tem-se ratificado o descompromisso da escola em desenvolver as habilidades motoras fundamentais nas crianças. Pesquisas sugerem que jogar por jogar, ainda que em um ambiente enriquecido por recursos materiais, não garante a proficiência motora, sendo crucial a mediação do professor neste processo (Palma, Pereira, \& Valentini, 2009).

Ainda sobre como as características pessoais afetam o contexto, o DSC 3.1 revela que apenas as crianças com melhor proficiência motora tinham oportunidades de intercâmbio social por meio de práticas esportivas, ratificando a quarta hipótese levantada neste trabalho. Fica explícito que a proficiência motora da criança orienta suas metas e disposições e provoca a demanda dos seus pares afetando as metas, valores, e expectativas que têm em relação a ela (Bronfenbrenner \& Morris, 2006). Crianças habilidosas apresentam este recurso como um facilitador da interação, pois têm mais oportunidades para liderar, particularmente nas atividades em que suas habilidades superiores se mostrem resolutivas (Miyabayashi \& Pimentel, 2011).

Reivindicar políticas públicas para implementar programas que desenvolvam a proficiência motora nas escolas e em ambientes comunitários durante a infância é essencial (Barnett et al., 2009). Todavia, os processos proximais serão tão mais positivos conforme o 
valor significativo que o tipo de habilidade represente para a sociedade, visto que depende claramente de suas crenças e metas (Gaspari et al., 2006). Pais e professores estarão mais propensos a equipar as crianças com aqueles tipos de habilidades que julguem ser mais essenciais para elas (Tudge et al., 1999). Assim, parece ser importante um investimento em campanhas publicitárias que esclareça a sociedade sobre a importância no desenvolvimento de habilidades motoras fundamentais, alertando para o fato de que o não desenvolvimento de tais habilidades na infância pode acarretar em um problema de saúde pública em fases posteriores do desenvolvimento (Barnett et al., 2009).

\section{CONCLUSÃO}

Ao centramos nossa atenção neste estudo para como os processos proximais eram desencadeados e sustentados no mesossistema (escola e projetos sociais esportivos) para desenvolver um recurso pessoal (habilidades motoras fundamentais) essencial na infância, e verificarmos como tal recurso pessoal interfere na forma como as crianças agem em outros contextos (intercâmbio social) rompemos com uma visão unidirecional de desenvolvimento no qual o contexto direciona o desenvolvimento da criança. Apoiados no modelo bioecológico, explicitamos neste estudo que as características da pessoa tanto são produto como produtoras do desenvolvimento.

O foco nos recursos pessoais da proficiência motora permitiu constatar que as habilidades motoras fundamentais das crianças são influenciadas por diferentes contextos (micromeso-exo e macrossistema), ao passo que tais recursos pessoais canalizam a ação das crianças em diferentes microssistemas. $\mathrm{O}$ modelo bioecológico permitiu constatar que as características pessoais da criança repercutem então na forma pela qual o contexto é experienciado por ela, bem como sobre os tipos de contextos para os quais ela é direcionada

Por fim, ao considerarmos o Tempo sóciohistórico no Modelo PPCT é possível constatar que a prevalência de atrasos motores nas crianças não ocorre num vácuo. A falta de condições de trabalho dos professores de educação física no Brasil carrega consigo raízes históricas. O que ocorre com a educação física é um reflexo do que acontece na educação pública como um todo. Particularmente ao que interessa neste estudo que era explicar por que tais atrasos motores ocorrem em populações empobrecidas, o estudo sugere que soluções para o problema são possíveis a curto e longo prazo. A curto prazo é essencial alterar a legislação de modo que faça com que o desenvolvimento das habilidades motoras fundamentais seja uma prioridade nos ciclos iniciais de ensino e que a longo prazo, uma verticalização curricular e capacitação docente é imperativo neste processo. Ademais, este estudo evidenciou que o modelo bioecológico se mostra como um excelente recurso metodológico para explicar determinados fenômenos relacionados ao desenvolvimento motor, sugerindo o uso do mesmo para explicar o porquê dos atrasos motores em outras culturas.

\footnotetext{
Agradecimentos:

Nossos agradecimentos in memoriam ao Prof. Dr. Ruy Jornada Krebs pelas relevantes contribuições prestadas nas discussões sobre a Teoria Bioecológica do Desenvolvimento Humano durante a elaboração do projeto de pesquisa que deu origem a este trabalho.
}

Conflito de Interesses:

Nada a declarar.

Financiamento:
Esse trabalho contou com apoio financeiro da
Coordenação de Aperfeiçoamento de Pessoal Docente
(CAPES) por meio da concessão de bolsa em nível de
doutorado e de apoio financeiro do Ministério da
Educação/Sesu em atendimento ao Edital PROEXT no
4/2011 e do Conselho Nacional de Desenvolvimento
Científico e Tecnológico-CNPq pela concessão de bolsa
em nível de Doutorado Acadêmico.

\section{REFERÊNCIAS}

Afonso, G. H., Freitas, D. H., Carmo, J. M., Lefèvre, J. A., Almeida, M. J., Lopes, V. P., ... Maia, J. (2009). Desempenho motor. Um estudo normativo e criterial em crianças da Região Autónoma da Madeira, Portugal. Revista Portuguesa de Ciências do Desporto, 9(2-3), 160-174. 
Barnett, L. M., Beurden, E. van, Morgan, P. J., Brooks, L. O., \& Beard, J. R. (2009). Childhood Motor Skill Proficiency as a Predictor of Adolescent Physical Activity. Journal of Adolescent Health, 44(3), 252-259. http://doi.org/10.1016/j.jadohealth.2008.07.00 4

Booth, M. L., Okely, T., McLellan, L., Phongsavan, P., Macaskill, P., Patterson, J., ... Holland, B. (1999). Mastery of fundamental motor skills among new south wales school students: Prevalence and sociodemographic distribution. Journal of Science and Medicine in Sport, 2(2), 93-105. http://doi.org/10.1016/S1440-2440(99)80189-3

Brasil LDB. Lei de Diretrizes e Bases da Educação Nacional, Pub. L. No. 9.394, de 20 de dezembro de 1996 que estabelece as diretrizes e bases da educação nacional. $5^{\text {a }}$ ed (2010).

Bronfenbrenner, U. (Ed.). (2005). Making human beings human: Bioecological perspectives on human development. Thousand Oaks, CA: SagePublications.

Bronfenbrenner, U., \& Morris, P. (2006). The bioecological model of human development. Em R. M. Lerner (Ed.), Handbook of Child Psychology (6. ${ }^{\mathrm{a}}$ ed., Vol. 1 Theoretical Models of Human Development, pp. 793-828). NY: John Wiley \& Sons.

Cecconello, A. M., \& Koller, S. H. (2003). Ecological insertion in community: a methodological proposal for studying families under risk situation. Psicologia: Reflexão e Crítica, 16(3), 515-524. http://doi.org/10.1590/S010279722003000300010

Cohen, K. E., Morgan, P. J., Plotnikoff, R. C., Callister, R., \& Lubans, D. R. (2014). Fundamental movement skills and physical activity among children living in low-income communities: a cross-sectional study. International Journal of Behavioral Nutrition and Physical Activity, 11(49), 1-9. http://doi.org/10.1186/1479-5868$11-49$

Conselho de Educação do Ceará (CEC). (2006). Resolução 412/2006. Obtido 12 de Julho de 2014, de http://www.cee.ce.gov.br/phocadownload/resol ucoes/RES-0412-2006.pdf

Costa, C. L. A., Nobre, G. C., Nobre, F. S. S., \& Valentini, N. C. (2014). Efeito de um programa de intervenção motora sobre o desenvolvimento motor de crianças em situação de risco social na região do Cariri-Ceará. Journal of Physical Education, 25(3), 353-364. http://doi.org/10.4025/reveducfis.v25i3.21968

Gabbard, C., \& Krebs, R. (2012). Studying Environmental Influence on Motor Development in Children. Physical Educator, 69(2), 136-149.

Gaspari, T., Souza Junior, O., Maciel, V., Impolcetto, F. M., Venâncio, L., Rosário, L. F., \& Darido, S. C. (2006). A realidade dos professores de Educação Física na escola: suas dificuldades e sugestões. Revista Mineira de educação física, 14(1), 109-137.

Goodway, J. D., Robinson, L. E., \& Crowe, H. (2010). Gender differences in fundamental motor skill development in disadvantaged preschoolers from two geographical regions. Research Quarterly for Exercise and Sport, 81(1), 17-24. http://doi.org/10.1080/02701367.2010.105996 24

Instituto de Pesquisa e Estratégia Econômica do Ceará (IPECE). (2011). Ceará em mapas: informações georreferenciadas e especializadas para os 184 municípios cearenses. Obtido 20 de Março de 2013, de http://www2.ipece.ce.gov.br/atlas/capitulo1/11 .htm

Lefèvre, F., \& Lefèvre, A. M. C. (2005). O discurso do sujeito coletivo: um novo enfoque em pesquisa qualitativa (desdobramentos) (2. ${ }^{\text {a }}$ ed.). Caxias do Sul, RS: Educs.

Mendes, A. D., \& Azevêdo, P. H. (2010). Políticas públicas de esporte e lazer \&amp; políticas públicas educacionais: promoção da educação física dentro e fora da escola ou dois pesos e duas medidas? Revista Brasileira de Ciências do Esporte, 32(1), 127-142. http://doi.org/10.1590/S010132892010000400009

Mesa, C. G. G., Estrada, J. A. C., Prado, J. L., \& González, C. R. (2009). Disponibilidad de las habilidades motrices em escolares de 4 a 14 años. Aplicabilidaddeltest de desarrollo motor grueso de Ulrich. Aula Abierta, 37(2), 19 - 28.

Miyabayashi, L. A., \& Pimentel, G. G. A. (2011). Interações sociais e proficiência motora em escoares do ensino fundamental. Revista Brasileira de Educação Física e Esporte, 25(4), $649-663$

Palma, M. S., Pereira, B., \& Valentini, N. C. (2009). Jogo com orientação: uma proposta metodológica para a educação física pré-escolar - DOI: 10.4025/reveducfis.v20i4.7014. Journal of Physical Education, 20(4), 529-541. http://doi.org/10.4025/reveducfisv20n4p529541

Papalia, D. E., Olds, S. W., \& Feldman, R. D. (2006). Desenvolvimento Humano (8. ${ }^{\mathrm{a}}$ ed.). Porto Alegre: ARTMED.

Rudio, F. C. (1978). Introdução ao projeto de pesquisa científica. Petrópolis: Vozes.

Spessato, B. C., Gabbard, C., Valentini, N., \& Rudisill, M. (2013). Gender differences in Brazilian children's fundamental movement skill performance. Early Child Development and Care, 183(7), 916-923. http://doi.org/10.1080/03004430.2012.689761

Tudge, J., Doucet, F., Odero, D., Tammeveski, P., Lee, S., Meltsas, M., \& Kulakova, N. (1999). Desenvolvimento infantil em contexto cultural: o impacto do engajamento de pré-escolares em atividades do cotidiano familiar. Interfaces, 2(1), 23-32. 
Ulrich, D. A. (2000). TGMD 2 - Test of gross motor development examinar'smanual (2. ${ }^{a}$ ed.). Austin, Texas: Pro-Ed.
Valentini, N. C. (2012). Validity and Reliability of the TGMD-2 for Brazilian Children. Journal of Motor Behavior, 44(4), 275-280. http://doi.org/10.1080/00222895.2012.700967 quando especificado em contrário e nos conteúdos retirados de outras fontes bibliográficas. 